\title{
A rare presentation of nutcracker syndrome and it's vascular managment
}

\author{
Nguessan Judicael Ahoury*1, Salami Fatima Adéniké ${ }^{2}$, Ndja Ange Patrick ${ }^{2}$, Cavez Nicolas ${ }^{3}$, Kouassi Paul Nzi ${ }^{1}$ \\ ${ }^{1}$ Department of Radiology, Institute of Cardiology, Abidjan, Côte d'Ivoire \\ ${ }^{2}$ Department of Radiology, University Hospital in Cocody, Côte d'Ivoire \\ ${ }^{3}$ Department of Angiography, Erasme Hospital in bruxelles, Belgium
}

Received: June 26, 2017

DOI: $10.5430 /$ jbgc.v7n1p13
Accepted: September 7, $2017 \quad$ Online Published: September 18, 2017

URL: https://doi.org/10.5430/jbgc.v7n1p13

\begin{abstract}
Nutcracker syndrome includes all the symptoms associated with the narrowing of the left renal vein (LRV). That narrowing occurs between the aorta and the Superior Mesenteric Artery (anterior) or vertebra (posterior). The symptoms are various and not specific but the patient sometimes presents hematuria with or without left flank pain. We report a case on a 42 years old woman, who was suffering from left flank pain for a long time aggravated during and after each pregnancy. The diagnosis of nutcracker syndrome was initially omitted. Abdominal pelvic Angio CT and venography were performed. We placed a percutaneous stent in the narrowed portion of the renal vein. The result was successful.
\end{abstract}

Key Words: Nutcracker syndrome, Pain, Left flank, Stent

\section{INTRODUCTION}

Nutcracker syndrome could be asymptomatic or could give rise to various manifestations. We present a case of patient with chronic intermittent colic missed diagnosis. Angio CT was helpful for diagnosis. During renal venography, we placed a percutaneous stent in the narrow portion of the renal successfully.

\section{CASE REPORT}

A 42 years old women refereed to our radiology department for abdominal pelvic Computed Tomography. She had a long history of abdominal pelvic pain predominant to the left flank. The pain was occasionally relieved by drugs. She had three child. These complaints were aggravated during and after each pregnancy and becoming more intensive. She had dyspareunia and gross hemorrhoids clipped at three times.
Since six months, the pain becoming more intensive and radiates to the medial thigh accentuated in upright position. Physical examination and laboratory test were normal. Abdominal Angio CT (see Figure 1) revealed the compression of the left renal vein (LRV) between the aorta and the superior mesenteric artery and several varices. The urogenital system was normal. A venography through the femoral vein puncture showed the stenosis of the renal vein(see Figure 2A). We placed a percutaneous stent in the narrow portion of the renal vein successfully (see Figure 2B).

\section{Discussion}

The LRV compression may be asymptomatic or responsible for a set of symptoms of variable intensity. It is a syndrome often missed. The patient can be seen by doctors of several specialties without identifying the cause. Notably, symp-

* Correspondence: Nguessan Judicael Ahoury; Email: ahouryjudi@yahoo.fr; Address: Department of Radiology, Institute of Cardiology, Abidjan, Côte d'Ivoire.

Published by Sciedu Press 
tomatic cases are called Nutcracker Syndrome, whereas nonsymptomatic patients may be described as having Nutcracker phenomenon. ${ }^{[1]}$

The most frequently described symptom is hematuria more often microscopic than macroscopic; it may be intermittent or occur after an effort. ${ }^{[1]}$ That hematuria is caused by rupture of thin-walled varices, due to venous hyper pressure into the collecting system. It causes anemia that requires blood transfusions occasionally.
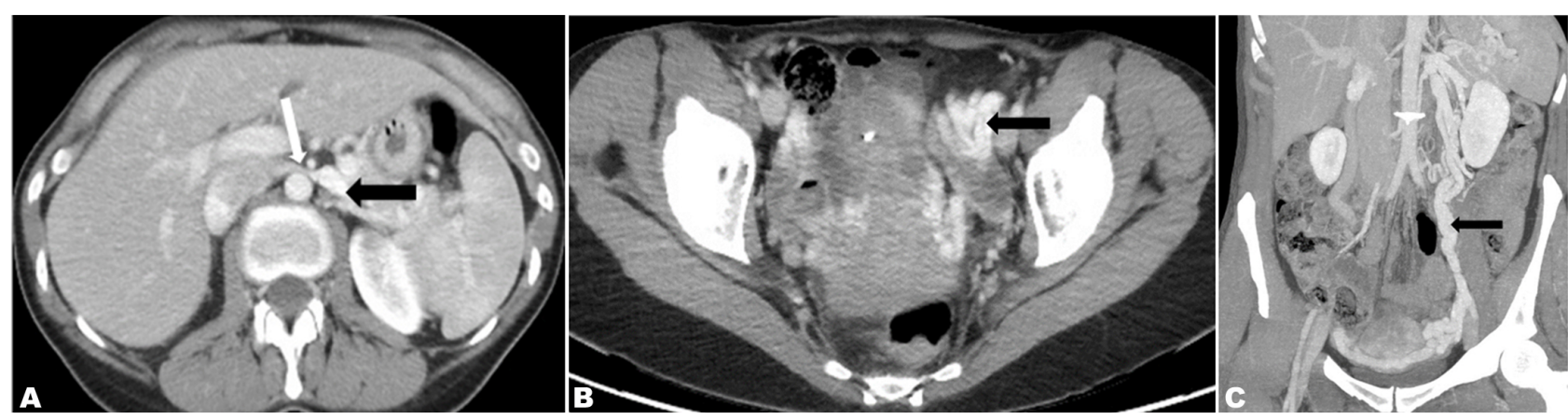

Figure 1. Abdominal Angio CT, transverse image portal phase demonstrates

(A) Compression of left renal vein (white arrow) between superior mesenteric artery and aorta and the dilation of its post aortic segment (black arrow); (B) Varicose dilatation of pelvic veins (black arrow); (C) Coronal reconstruction demonstrates several varicose dilatation of pelvic veins (black arrow)

Figure 2. Venography of vena cava and left renal vein shows

(A) narrowing of the vein behind vertebral body (arrow); (B) stent in the stenotic portion of the renal vein (arrow)
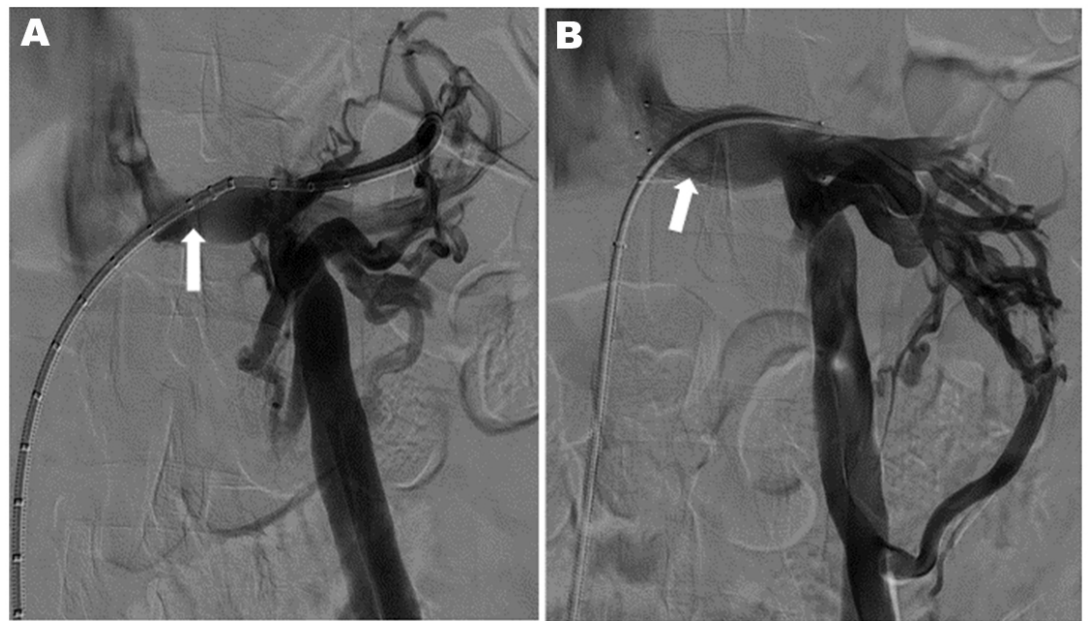

Pain increased by standing are caused by pelvic congestion due to venous stasis upstream of the clamp whose morphological expression corresponds to pelvic varices or varicoceles.

The patient may also present with albuminuria, abnormal menstruation, orthostatic intolerance. ${ }^{[2]}$ The symptoms can show exacerbation while sitting, standing, walking, generally by physical activity.

In this case, the patient had a long history of left flank pain sometimes relieved by drugs but any hematuria. The pain was the only symptom described but it wasn't specific. That can cause missed diagnosis. The pain was aggravated during and after each pregnancy probably to hypertension of pregnant uterus. Dyspareunia and hemorrhoids were noted.

NCS diagnosis can't go without imaging. Angio-CT is help- ful to measure the renal veins diameters and show the difference of the size to the hilum of the kidney and that of its passage between aorta and the Superior Mesenteric Artery or vertebra. Angio-CT highlights coexistence of abnormal venous collaterals and checks if they compensate for the narrowing or not. Other causes of hematuria and left flank pain are sought and eliminated by Angio-CT as well as associated malformations such as superior mesenteric artery syndrome, ${ }^{[3]}$ left renal hilar variations.

Abdominal pelvic Angio MR is also helpful to evaluate renal and pelvic veins. Other techniques such as color Doppler sonography, and angiography are used, but they have some limitations. Therefore, it is easily misdiagnosed or undiagnosed. Angio CT was performed in this case by showing the compressed LRV, several pelvic varices and absence of 
another cause of abdominal pain.

Measurement of venous pressure during renal venography is often used as diagnostic confirmation method ${ }^{[4,5]}$ but it isn't usually necessary.

Our patient was treated by implantation of stent under venography. During venography, we deployed a self-expanding nitinol stent in the stenotic portion of the LRV. The result was successful. We ordered the patient to take oral anticoagulants for six months to prevent intra-stent thrombosis.

The endovascular process is becoming the choice of treat- ment in this syndrome because of its minimal invasive nature and the physiological relief. ${ }^{[4,6]}$

\section{Conclusion}

LRV entrapment can be asymptomatic for a long time. However the chronic abdominal pelvic left flank pain must be the only sign. Angio CT is often sufficient for diagnosis. The percutaneous stenting is becoming the choice of treatment.

\section{CONFLicts of InTEREST Disclosure}

\section{REFERENCES}

[1] Kurklinsky AK, Rooke TW. Nutcracker phenomenon and nutcracker syndrome. Mayo Clin Proc. 2010; 85: 552-9. PMid: 20511485. https://doi.org/10.4065/mcp. 2009.0586

[2] Venkatachalam S, Bumpus K, Kapadia SR, et al. The nutcracker syndrome. Ann Vasc Surg. 2011; 25: 1154-64. PMid: 21439772. https://doi.org/10.1016/j.avsg.2011.01.002

[3] Mikail Inal, Daphan BU, Karadeniz Bilgili MY. Superior mesenteric artery syndrome accompanying with Nutcracker Syndrome: A Case Report Iran Red Crescent Med J. 2014; 16(10): 1-3. PMid: 25763192. https://doi.org/10.5812/ircmj. 14755
[4] Yu-Ming Chen, I-Kuan Wang, Koon-Kwan Ng, et al. Nutcracker Syndrome: An Overlooked Cause of Hematuria. Chang Gung Med J. 2002; 25: 700-4. PMid: 12518783.

[5] Ahmed K, Sampath R, Khan MS. Current trends in the diagnosis and management of the renal nutcracker syndrome: A review. Eur J Vasc Endovasc Surg. 2006; 31: 410-6. PMid: 16431142. https://doi.org/10.1016/j.ejvs.2005.05.045

[6] Hulsberg Paul C, McLoney E, Partovi S, et al. Minimally invasive treatments for venous compression syndromes. Cardiovasc Diagn Ther. 2016; 6: 582-92. PMid: 28123978. https ://doi.org/10.2 $1037 /$ cdt. 2016.10 .01 